\title{
The association between meat and fish consumption and bladder cancer risk: a pooled analysis of 11 cohort studies
}

\author{
Mostafa Dianatinasab ${ }^{1}$ - Anke Wesselius ${ }^{1}$ - $\cdot$ Tessa de Loeij $^{1}$ - Amin Salehi-Abargouei ${ }^{2}$ - Evan Y. W. Yu ${ }^{1}$. \\ Mohammad Fararouei $^{3} \cdot$ Maree Brinkman $^{1,4,5}$. Piet van den Brandt ${ }^{6} \cdot$ Emily White $^{7}$. Elisabete Weiderpass ${ }^{8}$. \\ Florence Le Calvez-Kelm ${ }^{8}$. Marc J. Gunter ${ }^{8} \cdot$ Inge Huybrechts $^{8}$. Fredrik Liedberg $^{9,10}$. Guri Skeie ${ }^{11}$. \\ Anne Tjonneland ${ }^{12,13} \cdot$ Elio Riboli $^{14} \cdot$ Maurice P. Zeegers ${ }^{1,15,16}$
}

Received: 29 December 2020 / Accepted: 12 May 2021 / Published online: 25 May 2021

(C) The Author(s) 2021

\begin{abstract}
Evidence on the effects of meat consumption from different sources on the risk of bladder cancer (BC) is limited and controversial. Therefore, this study aimed to evaluate the associations between meat consumption and $\mathrm{BC}$ risk using a pooled data approach. Individual data from 11 prospective cohorts comprising $2848 \mathrm{BC}$ cases and 515,697 non-cases with a total of $5,498,025$ person-years of follow-up was pooled and analysed to investigate the potential associations between total red meat and products, red meat, processed meat, poultry and total fish and BC risk. Hazard ratios (HRs), with corresponding 95\% confidence intervals (CIs), were estimated using Cox regression models stratified on cohort. Overall, an increased BC risk was found for high intake of organ meat (HR comparing highest with lowest tertile: 1.18, 95\% CI: 1.03, 1.36, p-trend $=0.03$ ). On the contrary, a marginally inverse association was observed for total fish intake and BC risk among men (HR comparing highest with lowest tertile: $0.79,95 \%$ CI $0.65,0.97$, p-trend $=0.04$ ). No associations were observed for other meat sources. Results of this prospective study suggest that organ meat consumption may be associated with BC development. Replication in large-scale prospective studies and investigation of possible causal mechanisms is needed.
\end{abstract}

Keywords Bladder cancer $\cdot$ Meat $\cdot$ Fish $\cdot$ Risk factor $\cdot$ Epidemiology

Anke Wesselius

anke.wesselius@maastrichtuniversity.nl

1 Department of Complex Genetics and Epidemiology, School of Nutrition and Translational Research in Metabolism, Maastricht University, Universiteitssingel40 (RoomC5.570), 6229 ER, Maastricht, The Netherlands

2 Nutrition and Food Security Research Center, Department of Nutrition, School of Public Health, Shahid Sadoughi University of Medical Sciences, Yazd, Iran

3 Department of Epidemiology, Shiraz University of Medical Sciences, Shiraz, Iran

4 Department of Clinical Studies and Nutritional Epidemiology, Nutrition Biomed Research Institute, Melbourne, Australia

5 Cancer Epidemiology Division, Cancer Council Victoria, 615 St Kilda Road, Melbourne, VIC 3004, Australia

6 Department of Epidemiology, Schools for Oncology and Developmental Biology and Public Health and Primary Care, Maastricht University Medical Centre, Maastricht, The Netherlands
7 Fred Hutchinson Cancer Research Center, Seattle, WA, USA

8 International Agency for Research on Cancer World Health Organization, Lyon, France

9 Department of Urology, Skåne University Hospital, Malmö, Sweden

10 Institution of Translational Medicine, Lund University, Malmö, Sweden

11 Department of Community Medicine, UIT The Arctic University of Norway, Troms $\varnothing$, Norway

12 Danish Cancer Society Research Center, Copenhagen, Denmark

13 Department of Public Health, University of Copenhagen, Copenhagen, Denmark

14 Department of Epidemiology and Biostatistics, School of Public Health, Imperial College London, London, UK

15 CAPHRI School for Public Health and Primary Care, Maastricht University, Maastricht, The Netherlands

16 School of Cancer Sciences, University of Birmingham, Birmingham, UK 


$\begin{array}{ll}\text { Abbreviations } \\ \text { BC } & \text { Bladder cancer } \\ \text { BLEND } & \begin{array}{l}\text { Bladder cancer Epidemiology and Nutritional } \\ \text { Determinants }\end{array} \\ \text { BMI } & \begin{array}{l}\text { Body Mass Index } \\ \text { CI }\end{array} \\ \text { EPIC } & \text { Confidence Interval } \\ \text { EFQ } & \text { Food Frequency Questionnaire } \\ \text { g } & \text { Gram } \\ \text { HRs } & \text { Hazard Ratios } \\ \text { HCAs } & \text { Heterocyclic Amines } \\ \text { ICD-O } & \text { International Classification of Diseases for } \\ & \text { Oncology } \\ \text { kcal } & \text { Kilocalorie } \\ \text { ml } & \text { Milliliter } \\ \text { MIBC } & \text { Muscle-invasive BC } \\ \text { NOC } & \text { N-nitroso Compounds } \\ \text { NMIBC } & \text { Non-muscle-invasive BC } \\ \text { NLCS } & \text { The Netherlands Cohort Study } \\ \text { PLCO } & \text { The Prostate, Lung, Colorectal, and Ovarian } \\ & \text { cohort study } \\ \text { PAHs } & \text { Polycyclic aromatic hydrocarbons } \\ \text { RR } & \text { Relative Risk } \\ \text { SD } & \text { Standard Deviation } \\ \text { VITAL } & \text { VITamins and Lifestyle study } \\ \text { WCRF } & \text { World Cancer Research Fund International }\end{array}$

\section{Introduction}

Cancer of the bladder (BC) is among the top ten most common cancer types in the world, with approximately 573,000 new cases and 213,000 deaths [1]. Incidence rates of BC are the highest in Southern and Eastern Europe Africa and the Middle East, and in North America [2]. BC occurs mainly in men and elderly [1] and approximately $75 \%$ of the bladder cancers are non-muscle-invasive (NMIBC) which require intensive treatment and follow-up measures, thereby posing a large burden on national health care budgets [3]. Epidemiological studies have identified several factors which potentially influence BC risk, including; sex, smoking, age and certain occupations [3, 4]. Well-established BC carcinogens include aromatic amines like heterocyclic amines (HCAs), polycyclic aromatic hydrocarbons (PAHs) and arsenic and repetitive urinary tract infections have also been reported to increase $\mathrm{BC}$ risk [5]. In addition, a wider range of evidence is becoming available on the plausible role of dietary factors in BC occurrence [5]. However, the latest World Cancer Research Fund International (WCRF) report stated that evidence from epidemiologic studies on the association between diet and $\mathrm{BC}$ is still scarce and largely inconsistent [6].
Meat is a rich source of multiple potentially carcinogenic compounds, including nitrate, nitrite, HCAs and PAHs, with a known effect on tumor growth induction [7-10]. Since these compounds are excreted in the urine and therefore come in close contact with the inner lining of the bladder wall, these components might play an important role in BC development [11].

There is however limited and inconsistent epidemiological evidence on the association between meat consumption and BC. While a Swedish cohort study found no association between the consumption of red meat, processed meat, poultry, or fried meats/fish and BC risk [12], other prospective cohort studies suggested an increased BC risk with cumulative consumption of processed red meat $[13,14]$. A positive association between meat consumption and $\mathrm{BC}$ risk was also confirmed by a meta-analysis, including five cohort and eight case-control studies from all over the world. It was shown that an increment of $50 \mathrm{~g}$ of processed meat per day was associated with $20 \%$ increased risk of BC [15]. In addition, the authors showed that red meat consumption was associated with BC, with a $51 \%$ increased risk per increment of $100 \mathrm{~g}$ per day. However, this association with red meat consumption could only be observed among the included case-control studies. A more recent meta-analysis only identified a positive association between red and processed meat among Americans, while an absence of an association was observed for individuals from other continents [16].

These controversial findings might be due to the small sample sizes of previously conducted studies, which consequently would lack statistical power to detect significant associations. Although meta-analysis might overcome this power issue, they solely rely on previously published data, thereby potentially introducing reporting bias. The present study, therefore, aims to provide a more comprehensive estimate for the associations between meat consumption and $\mathrm{BC}$ risk, by pooling individual data from 11 cohort studies, thereby not only increasing the power to detect small effect sizes, but also allowing for data homogenization and common adjustment for potential confounding factors.

\section{Methods}

\section{Study sample}

Data were derived from the BLadder cancer Epidemiology and Nutritional Determinants consortium (BLEND) [17]. BLEND is a large international epidemiology consortium, aimed to pool available data from epidemiological studies on diet and BC [17]. BLEND consists of 19 case-control studies and 16 cohort studies. Eleven cohort studies, with a total of 518,545 participants, 2848 of whom developed incident BC, had sufficient information on both meat and 
fish consumption, and on the most important covariates gender and smoking, to be eligible for inclusion in the present study. These studies originated from 11 countries [i.e. Europe: European Prospective Investigation into Cancer and Nutrition cohort studies (EPIC) [18] (Denmark [19], France [20], Germany [21], Italy [22], The Netherlands [23], Norway [24], Spain [25], Sweden [26, 27], United Kingdom $[28,29]$ ), Netherlands cohort study (NLCS) [30]; and North America: VITamins and Lifestyle cohort study (VITAL) [31]].

\section{Data collection and pre-processing}

Details on the protocol of the BLEND consortium have been described in the BLEND methodology paper [17]. Briefly, the primary data from all the included studies were assembled into an integrated database. Data were checked and the food consumption was converted to grams per day (g/day) by the use of country specific food tables and the frequency responses. National specific standard portions sizes for each food item were used to calculate consumption in g/day. Each study ascertained incident bladder cancer cases, defined to include all subjects with urinary bladder neoplasms according to the International Classification of Diseases for Oncology (ICD-O-3 code C67) using population-based cancer registries, health insurance records, or medical records [32, 33]. Dietary data were obtained using self-administered or trained interviewer administered food frequency questionnaire (FFQ) that was validated on either food groups $[31,34,35]$, and/or energy intake [35, 36]. For each study, participants were asked to report on their usual intake during the year before study enrolment of meat and fish. These data were harmonized using the hierarchal Eurocode 2 food coding system developed by the European Union [37], with weekly, monthly or yearly intake converted to grams ( $\mathrm{g}$ ) per day. This resulted in an aggregated dataset with unified dietary intakes across the different studies included.

\section{Dietary meat consumption}

By conducting a comprehensive review of the literature, we were able to use a more common definition of different meat categories $[12,13,15,38]$. Dietary meat consumptions were categorized in the following groups including total meat and meat products (all meat groups except fish), total red meats and products (total meat and meat products minus poultry), red meat (beef, veal, mutton/lamb and pork), processed meats (preserved meat and meat products), organ meat (liver and other offal), poultry, and fish (fish and fish products). As a result of data availability, red meat, processed meat, organ meat, poultry, and fish consumption were calculated in grams per 1000 kilocalories per day $(\mathrm{g} / 1000 \mathrm{kcal} / \mathrm{day}$, nutrient density method), to account for total energy intake and reduce extraneous variation in dietary intakes [39, 40], and were categorized into tertiles for individual meat types [40]. Then, dietary meat consumptions were divided into 3 groups based on a tertile ordered distribution: low consumption (tertile 1), medium consumption (tertile 2) and high consumption (tertile 3 ).

\section{Other variables}

In addition to dietary consumption information, other baseline data included study characteristics including study design, method of dietary assessment, recall period of dietary consumption and geographical region, demographic information (age, sex and ethnicity), pathology of BC (nonmuscle-invasive bladder cancer [NMIBC] and muscle-invasive bladder cancer [MIBC]), and smoking status (current/ former/never) and quantity (packs/year).

\section{Statistical analyses}

Baseline characteristics of the study participants, meat sources and other potential confounders were compared between case and non-case groups using independent samples t-test, for continuous variables, or chi-square for categorical variables. Cox proportional hazard modelling approach was used with age at recruitment as the starting point on the time scale to assess the association between consumptions of meat and $\mathrm{BC}$ risk. Hazard ratios (HRs) and $95 \%$ confidence intervals (CIs) for developing $\mathrm{BC}$ were calculated with the first tertile assigned as reference group. The proportional hazards assumption was examined graphically, and we found no apparent violation to the assumption. Survival time was estimated by subtracting age at exit by age at entry in the cohort as $\mathrm{T} 0$, thereby correcting for age in the analysis. Also, study was included as a random effect. The Cox regression models were performed as crude, and based on literature review adjusted model-1 for: age, sex, smoking status (never, former or current smoker), total energy intake in kilocalories, and additionally for: vegetables and fruits consumption (model-2). In addition, when testing for white meat and fish consumption analyses were corrected for red meat intake and vice versa (model 3 ).

To understand the relevance of plausible effect modification, interaction terms for sex, age and smoking status, and meat- and fish consumption were alternately added to the fully adjusted regression models. This was done by adding the multiplication of meat- and fish consumption in tertiles and: (a) the categorized age $(<40,40-50,50-60,>60)$, (b) gender, (c) smoking status (current, former and smokers). The Wald-test was used to test for the presence of interaction, and p-interaction $<0.05$ was considered statistically significant. Based on the knowledge that $\mathrm{BC}$ subtype (i.e. 
NMIBC and MIBC) have a different etiology, additional subgroup analyses were performed on BC subtypes.

We further assessed the potential dose-response relations of meat consumptions with BC risk by fractional polynomial regression using the ln (natural logarithm) of the HRs (model 3) across categories of consumption, in which the best-fitting second-order fractional polynomial regression model was defined as the model with the lowest deviance $[40,41]$. A likelihood ratio test was used to assess the difference between the nonlinear (i.e., the absolute dose and dose squared) and linear (i.e., the absolute dose) models to test for linearity or nonlinearity [41]. For this, we categorized each source meat to six groups including (a) total meat and meat products, (b) red meats, (c) processed meats, (d) organ meats, (e) poultry and (f) fish and fish products into 10 doses (g/1000 kcal/day) according to the range of consumption of meat sources, by which the intervals of each consumption were different. $\mathrm{P}$ values for trend were estimated by assigning medians to each category of consumption as a continuous variable.
Finally, in order to determine the single study effect, sensitivity analyses were performed by removing each individual study in turn from the main analysis. All statistical analyses were performed using Stata/SE version 14.2. $P$ values less than 0.05 were considered as statistically significant.

\section{Results}

\section{Baseline characteristics}

The baseline characteristics of the study population are shown in Table 1. Baseline characteristics for the 11 included cohort studies individually are shown in Supplementary Table 1 . Dietary data from 518,545 study participants, including 2848 incident cases and 515,697 non-cases with a total of 5,498,025 person-years of follow-up (median follow-up: 11.3 years) were analyzed. The study population consisted of 1088 NMIBC cases (63\%) and 648 MIBC cases $(37 \%)$.
Table 1 Baseline characteristics meat sources among non-cases and bladder cancer cases in the END international study

\begin{tabular}{|c|c|c|c|}
\hline Categories of data & $\begin{array}{l}\text { Cases } \\
\mathrm{n}=2848\end{array}$ & $\begin{array}{l}\text { Non-cases } \\
\mathrm{n}=515,697\end{array}$ & $P$ value \\
\hline Baseline age year (mean $(S D))$ & $60.6(7.28)$ & $52.5(10.09)$ & $<0.001^{\wedge}$ \\
\hline Person-year & $\begin{array}{l}\text { Total: } 21,210.08 \\
\text { Median: } 7.45\end{array}$ & $\begin{array}{l}\text { Total: } 5,476,815 \\
\text { Median: } 10.62\end{array}$ & $<0.001^{\wedge}$ \\
\hline $\operatorname{Sex} n(\%)$ & & & $<0.001^{\wedge}$ \\
\hline Men & $2144(75.3)$ & $164,953(32.0)$ & \\
\hline Women & $704(24.7)$ & $350,744(68.0)$ & \\
\hline Smoking status $n(\%)$ & & & $<0.001^{*}$ \\
\hline Current & $1118(39.3)$ & $107,108(20.8)$ & \\
\hline Former & $1183(41.5)$ & $154,474(30.0)$ & \\
\hline Never & $547(19.2)$ & $254,115(49.2)$ & \\
\hline \multicolumn{4}{|c|}{ Dietary meat sources, g/1000 kcal/day (mean (SD)) } \\
\hline Total meat and meat products & $49.06(28.4)$ & $49.38(30.65)$ & $0.571^{\wedge}$ \\
\hline Total red meats and products & $39.98(26.37)$ & $39.21(27.40)$ & $0.135^{\wedge}$ \\
\hline Red meats & $17.38(17.96)$ & $15.62(17.15)$ & $<0.001^{\wedge}$ \\
\hline Processed meats & $16.34(13.93)$ & $15.42(13.08)$ & $<0.001^{\wedge}$ \\
\hline Organ meats & $3.11(4.43)$ & $2.54(4.53)$ & $<0.001^{\wedge}$ \\
\hline Poultry & $8.87(9.95)$ & $9.99(11.56)$ & $0.731^{\wedge}$ \\
\hline Fish and fish products & $3.58(5.42)$ & $5.76(6.83)$ & $<0.001^{\wedge}$ \\
\hline \multicolumn{4}{|l|}{ Potential confounders } \\
\hline Energy intake, kcal/day (mean (SD) & $2179.13(630.32)$ & $2051.59(642.12)$ & $<0.001^{\wedge}$ \\
\hline Fruits, g/1000 kcal/day (mean (SD)) & $77.39(77.63)$ & $91.74(222.40)$ & $0.776^{\wedge}$ \\
\hline Vegetables, g/1000 kcal/day (mean (SD)) & $135.88(103.18)$ & $151.51(380.96)$ & $<0.001^{\wedge}$ \\
\hline \multicolumn{4}{|l|}{ Ethnicity (\%) } \\
\hline Caucasian & $2834(99.6)$ & $511,934(99.3)$ & $0.094^{*}$ \\
\hline Non-Caucasian & $12(0.4)$ & $3507(0.7)$ & \\
\hline
\end{tabular}

$S D$ standard deviation, $g$ gram, $m g$ milligram, $m l$ milliliters, $k c a l$ kilocalorie

${ }^{\wedge}$ Based on independent sample t-test. *Based on Chi-2 test 
In total, 167,095 (32\%) men and 351,444 (68\%) women were included. As shown in Table 1, compared to non-cases, $\mathrm{BC}$ cases were more likely to be men (75\%) and to be current $(39 \%)$ or former smokers $(41 \%)$. Mean $( \pm$ SD) age for was $60.6( \pm 7.3)$ for cases and $52.5( \pm 10.1)$ for non-cases. The median (interquartile) time from exposure collection to $\mathrm{BC}$ diagnosis was 8.5 years $(4.9,12.0)$. Almost all participants were Caucasian [i.e., $99.6 \%$ of the cases and $99.3 \%$ of the non-case $(P=0.09)]$.

Regarding dietary factors, compared to non-cases, cases had a higher mean $( \pm \mathrm{SD})$ consumption of all assessed food items (i.e. total red meat and products 39.9 (26.4) vs. 39.2 (27.4), red meats 17.4 (17.9) vs. 15.6 (17.1), processed meats 16.3 (13.9) vs. 15.4 (13.1), organ meats 3.1 (4.4) vs. 2.5 (4.5), energy intake 2179.1 (630.3) vs. 2051.6 (642.1), except for poultry (8.9 (9.9) vs. 10.0 (11.6)), fish and fish products (3.58 (5.4) vs. $5.7(6.8)$ ), vegetables (135.9 (103.2) vs. 151.5 (380.9)), and fruits (77.4 (77.6) vs. 91.7 (222.4)), which showed to be consumed in a lower amount among cases (Table 1).

\section{Associations between meat consumption and BC risk comparing high to low consumption}

The results of the Cox regression for subsequent categories of meat consumption are shown in Table 2 . We found that greater consumption of organ meats was associated with an increased risk of $\mathrm{BC}$ (model 2: HR comparing highest to lowest tertile: $1.18,95 \% \mathrm{CI}: 1.03,1.36$, p-trend $=0.03$ ). This association remained stable after additional adjustment for poultry meat and fish intake (model 3: HR comparing highest to lowest tertile: $1.21,95 \%$ CI: $1.05,1.38$, p-trend $=0.014$ ). An inverse association between higher consumption of poultry meat and risk of $\mathrm{BC}$ was observed (model 2: HR comparing highest to lowest tertile: $0.71,95 \%$ CI: $0.65,0.78$, p-trend $<0.001)$. However, after adjustment for red meat intake this association disappeared (model 3: HR comparing highest to lowest tertile: $0.9895 \% \mathrm{CI}$ : $0.84,1.12$, p-trend 0.54) (Table 2). Furthermore, a marginally non-significant association between total fish and fish products (model 2: HR comparing highest with lowest tertile: $0.84,95 \%$ CI $0.72,1.00$, p-trend $=0.08$; model 3: HR comparing highest with lowest tertile: $0.89,95 \%$ CI 0.63 , 1.25 , p-trend $=0.369$ ) and the risk of $\mathrm{BC}$ was observed. No associations were found for any other meat sources.

\section{Subgroup analysis}

A significant interaction was observed between fish consumption and gender and smoking (p-interaction $=0.03$, 0.01 , respectively). No other interaction terms showed to be relevant.
An inverse association between total fish and fish products consumption and $\mathrm{BC}$ risk in men (model 2: HR comparing highest with lowest tertile: $0.81,95 \%$ CI: $0.67,0.98$, p-trend $=0.03$; model 3: HR comparing highest with lowest tertile: $0.79,95 \%$ CI: $0.65,0.97$, p-trend $=0.04$ ) was observed, but no association was found in women (model 2: HR comparing highest with lowest tertile: $0.96,95 \%$ CI: $0.63,1.45$, p-trend $=0.69$; and model 3: HR comparing highest with lowest tertile: $1.07,95 \% \mathrm{CI}: 0.76,1.51$, p-trend $=0.658, p$-heterogeneity $=0.02)($ Table 3$)$. No significant association for fish intake and $\mathrm{BC}$ risk was observed in the different smoking categories (Table 3).

Stratified results for BC subtypes (i.e., NMIBC and MIBC) showed no different effect of any of the meat- and fish intake on the different BC subtype risks (p-heterogeneity for all >0.05) (Supplementary Table 2).

\section{Dose-response and sensitivity analyses}

Dose-response relationships between different sources of meat consumptions and the risk of $\mathrm{BC}$ are displayed in Fig. 1. Although cox-regression showed a significantly increased BC risk for organ meat consumption of over $15 \mathrm{~g} / 1000 \mathrm{kcal} /$ day, no significant dose-response relationship was observed for any meat-type and neither for fish (Fig. 1).

In order to determine the single study effect, sensitivity analyses were performed by removing each individual study in turn from the main analysis. Results showed that the main finding remained robust.

\section{Discussion}

By bringing together the world's data on meat and fish consumption and $\mathrm{BC}$ risk, this large prospective study demonstrates an overall significant association between high consumption of organ meat and $\mathrm{BC}$ risk and a slightly inverse association for high consumption of fish among men.

Epidemiological evidence on the association between organ meats and $\mathrm{BC}$ risk is mainly lacking. To our knowledge, only one previously conducted case-control study assessed this association [42]. In line with results from the present study, the authors found an increased BC risk among South and East Chinese individuals [42]. A possible explanation for the observed association between organ meat and BC risk, is the high fat content (especially saturated fats) of organ meat, which has been reported to increase the BC risk [43, 44]. In addition, it has been suggested that the cooking procedure of fat-rich meat forms mutagens and consequently affect $\mathrm{BC}$ risk [45-47]. As such, it is reported that different procedures of cooking meat i.e.; at higher temperatures (roasting) or 
Table 2 Hazard ratio (HR) and 95\% confidence interval (CI) of the association of meat and meat types, and risk of BC based on tertiles of meat and meat types

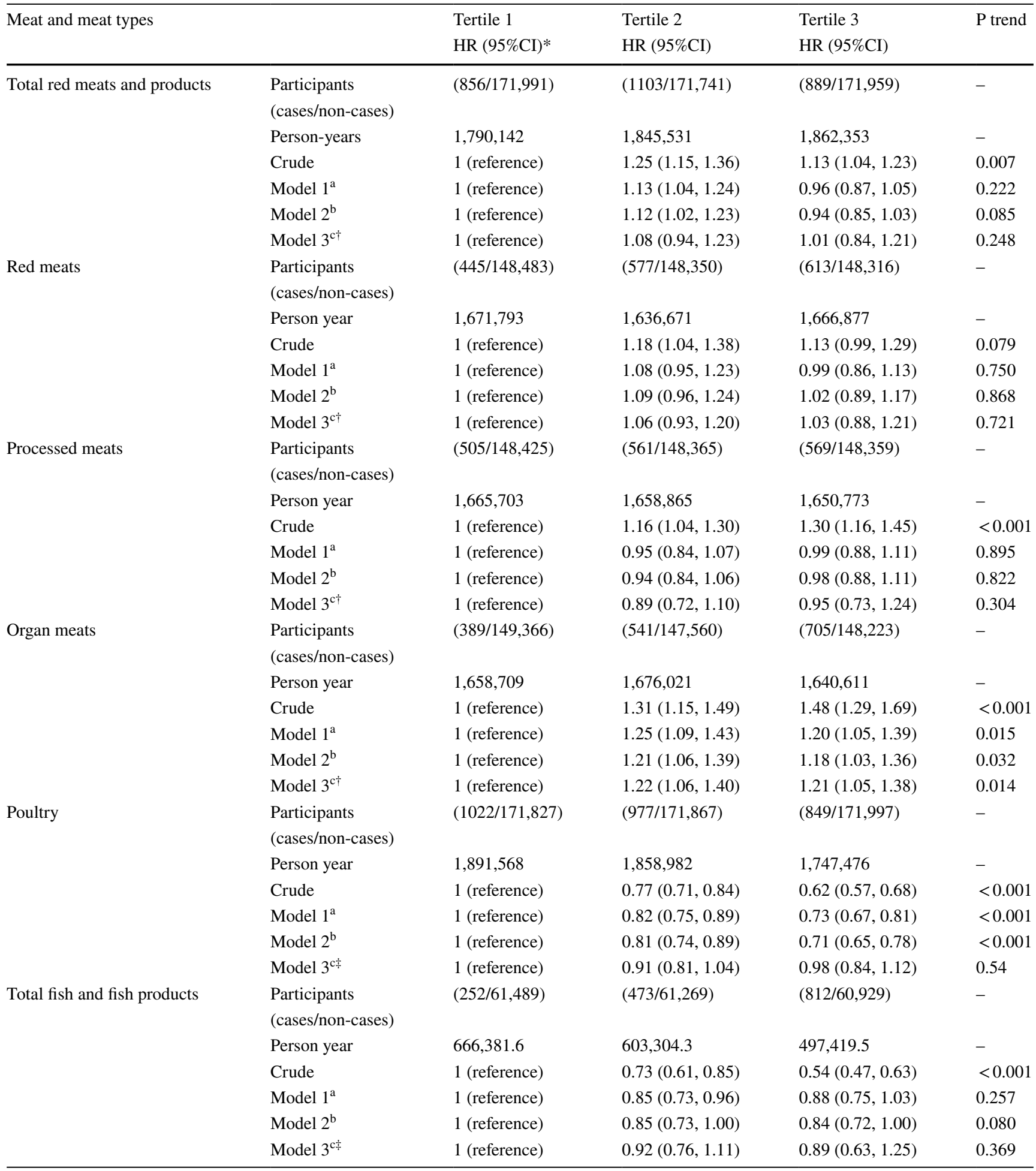

*HR hazard ratio, $C I$ confidence interval

${ }^{a}$ Adjusted for age, sex, smoking status and total energy intake

${ }^{\mathbf{b}}$ Adjusted for model $1+$ vegetables and fruits intakes

${ }^{\mathrm{c}}$ Adjusted for $\pitchfork$ model $2+$ poultry and fish intake $\neq$ model $2+$ red meat intake 
Table 3 Hazard ratio (HR) and 95\% confidence interval (CI) of the association of fish consumption, and risk of BC based on tertiles of intakes by gender and smoking status

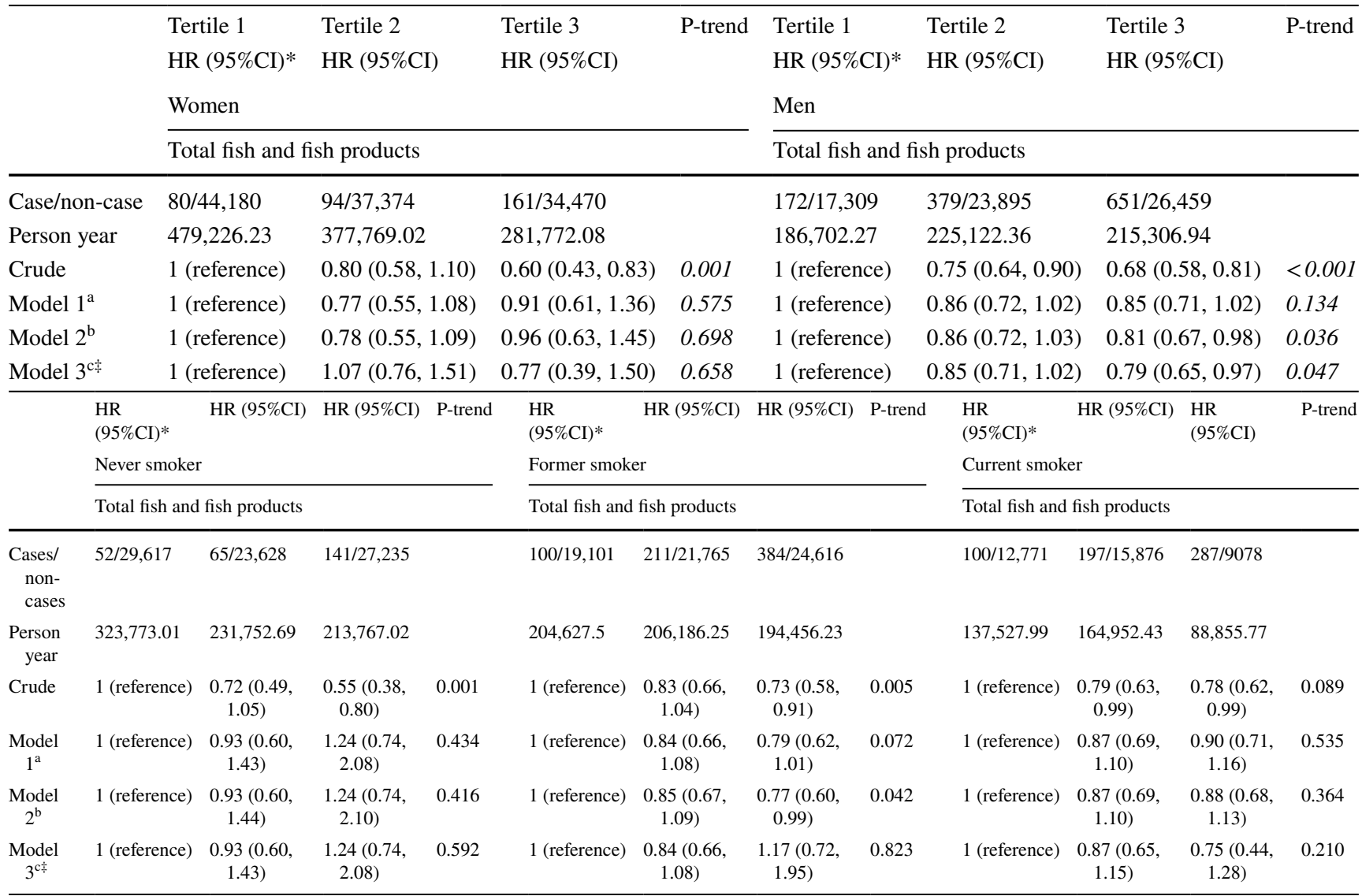

*HR hazard ratio, $C I$ confidence interval

${ }^{a}$ Adjusted for age, sex, and total energy intake

${ }^{\mathrm{b}}$ Adjusted for model $1+$ vegetables and fruits intakes

c ${ }^{\text {}}$ Adjusted for model $2+$ red meat intake

for prolonged times (e.g. stewing), were associated with an increased BC risk [48]. Another possible explanation could be the fact that most organ meats are high in toxins [49], which might cause dysbiosis of the urinary tract, thereby indirectly causing an increased BC risk [50-52].

Bioassays and epidemiological studies indicated that tobacco smoking might modify the effect of dietary fat and cancer risk by enhancing the carcinogenic potency of meat and exerted a synergistic effect on cancer risk [53-55]. Moreover, the N-nitroso components of meat, the nitrosation of nicotine during tobacco processing, and the tobacco-specific nitrosamines resulted from cigarette smoking might lead to an increased total $\mathrm{N}$-nitroso compound consumption, thereby increasing the $\mathrm{BC}$ risk of meat in current smokers [56]. However, in the present study no interaction between meat consumption and smoking status could be observed. This might be due residual confounding, which could not be assess in the present study.
In the present study we found no significant association between poultry intake and $\mathrm{BC}$ risk. This is in line with the results of a meta-analysis of eight studies, also revealing a non-significant association between poultry and BC risk (RR: 0.77, 95\% CI 0.48, 1.06) [57]. However, the NIHAARP Diet and Health study reported a statistically significant decreased $\mathrm{BC}$ risk associated with a $10 \mathrm{~g} / \mathrm{per}$ in white meat consumption [38]. It is suggested that, compared to red meat, white meat (including poultry) contains less saturated fat and heme iron, potential inducers of oxidative stress and DNA damage [58], and release less mutagenic substitutes during the cooking procedure. It could, therefore, be possible that the previously observed inverse association between poultry and $\mathrm{BC}$ risk was not due to a protective effect of poultry itself, but rather due to a reduced intake of red meat, for which only limited adjustment was performed.

In the present study we found an inverse association between fish consumption and $\mathrm{BC}$ risk in men, but not in women. Although the evidence of the association of fish 

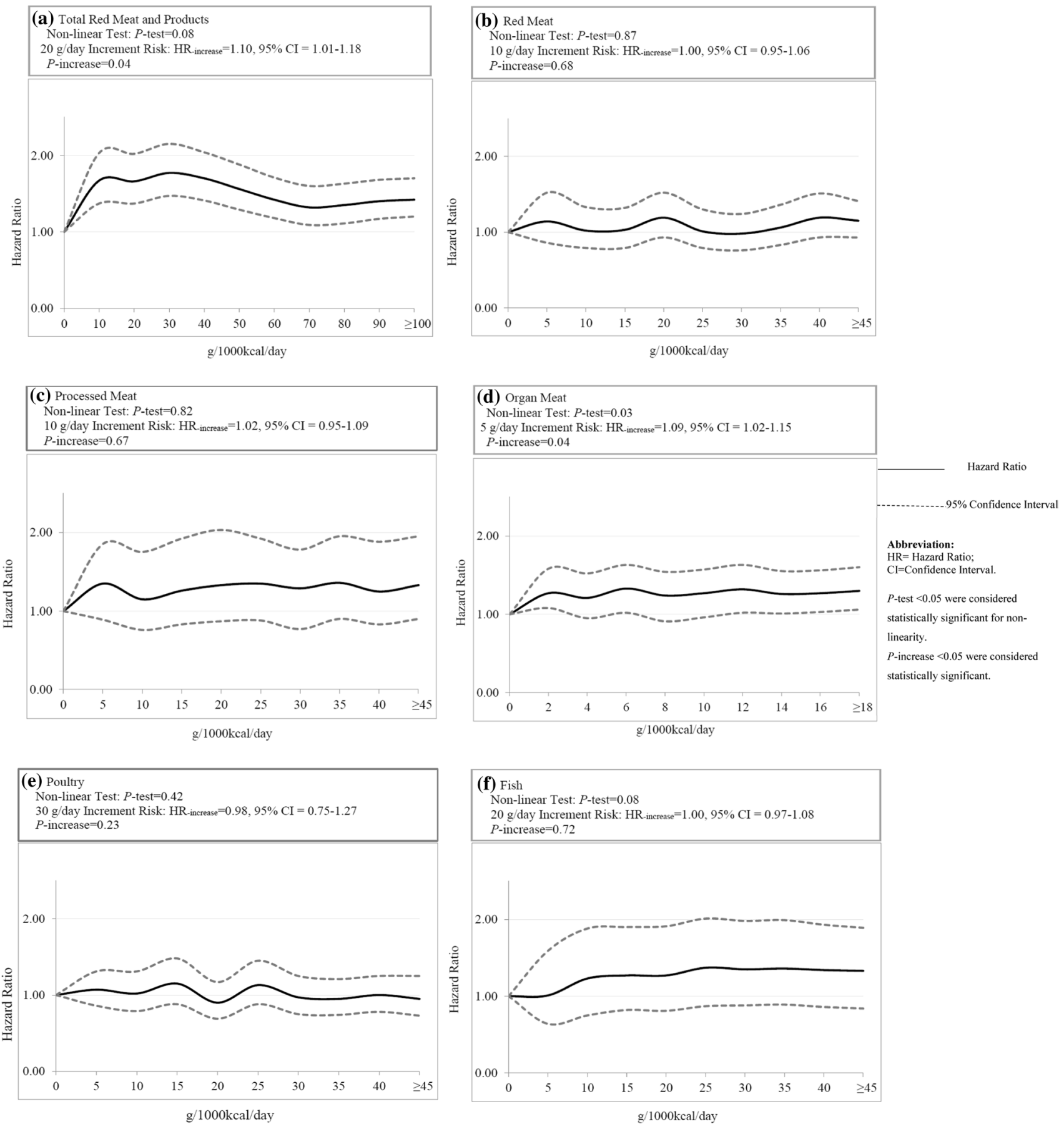

Fig. 1 Dose-response relationships between meat intakes and the risk of bladder cancer among a total red meats and products; $\mathbf{b}$ red meats; c processed meats; $\mathbf{d}$ organ meats; e poultry and $\mathbf{f}$ total fish and fish products. The solid lines represent the hazard ratios (HRs); the dashed lines represent the $95 \%$ confidence intervals (CIs) for the trend. The HRs were adjusted for age (years, continuous), sex

consumption and $\mathrm{BC}$ is scarce, a previously conducted Spanish case-control study also reported an inverse association between fish intake and BC risk [59]. This protective effect of fish on $\mathrm{BC}$ risk might possibly be due to the concentrated

(men or women), smoking (never smokers, former smokers or current smokers), energy intake (kcal/day, continuous), vegetable intake (g/1000 kcal/day, continuous), fruit intake $(\mathrm{g} / 1000 \mathrm{kcal} / \mathrm{day}$, continuous) poultry ( $\mathrm{g} / 1000 \mathrm{kcal} /$ day, continuous) and fish $(\mathrm{g} / 1000 \mathrm{kcal} / \mathrm{day}$, continuous) intake or red meat intake ( $\mathrm{g} / 1000 \mathrm{kcal} / \mathrm{day}$, continuous) (model 3). $g$ gram; $k c a l$ kilocalorie. Referent group was non-intake

doses of anti-inflammatory, long-chain n-3 fatty acids in fish, shown to inhibit cancer development and progression [60]. On the contrary, however, several observation studies on fish intake and BC risk observed a null-association [12, 61, 62]. 
It is suggested that the way fish is served may be quite different between cultures and also preparation, conservation, and processing methods may have deleterious health effects (e.g. Cantonese-style salted fish or heavily battered and deep fried) [63]. So, future research is needed to elucidate the exact role of fish on the development of $\mathrm{BC}$, considering also differences in fish processing.

Overall, a null-association between red- and processed meat consumption and $\mathrm{BC}$ risk was observed. Although this is in line with several previously conducted studies, including three cohort studies and a meta-analysis, [12-14, 57], other studies, including two meta-analyses and a cohort study, reported a direct negative association between both red- and processed meat consumption and the $\mathrm{BC}$ risk [15, $16,64]$. Potential mechanisms underlying the association of meat consumption and $\mathrm{BC}$ risk are still unclear. Therefore, future research is warranted to clarify the underlying mechanisms.

\section{Strengths and limitations}

So far, the BLEND database is the largest pooled prospective cohort study investigating the associations between consumption of different sources of meat and the risk of developing $\mathrm{BC}$ and allows enough statistical power to conduct detailed analyses in detecting small effects. The use of individual participant data enables adjustments to be made for the same confounders across all studies. Additionally, eliminating possible sources of heterogeneity with the use of prospective cohort studies only, precludes recall bias which commonly occur in case-control and retrospective cohort studies.

Alternatively, several limitations to our study should be considered. Some information in the BLEND database was only in portions per week. This was converted to grams per day using the BLEND Nutrient 100-g database. However, the conversions were not country specific. Also, limited information was available for some potential risk factors of $\mathrm{BC}$, such as BMI, physical inactivity, socioeconomic status, and occupational exposures to carcinogenic chemicals. The possibility to adjust for these factors will provide more accurate risk estimates. Moreover, it is a possibility that people with a high intake of fish and poultry might have generally healthier lifestyles and diets than those with a low intake, thus we could not rule out the possibility that some of the associations could be or partially due to unmeasured factors related to a healthy lifestyle than to purely white meat intakes [65]. However, the current literature suggests only a small proportion of $\mathrm{BC}$ cases can be attributed to lifestyle and environmental factors [66]. In addition, we were unable to take into account possible changes in dietary and lifestyle habits over time, which would better reflect the effect of long-term diet. Furthermore, it is suggested that meat might be involved in the bladder carcinogenesis via multiple potentially carcinogenic fish/meat-related compounds related to cooking and processing, including nitrate, nitrite, HCAs, and PAHs. However, in this study there was no information on meat preparation or cooking methods. Besides, for most cohorts, the exposure variable was assessed by FFQs, therefore, measurement error and misclassification of study participants in terms of the exposure and outcome are unavoidable. Likewise, information bias, as a consequence of self-reported information on food consumption is a common bias in nutritional studies [67]. However, the strength and direction of this bias should not be significantly different between cases and non-cases, suggesting that the impact of information bias on our findings might be minimal. Finally, the present study sample consisted mostly of Caucasians, and this may limit the generalizability of our results to other racial/ethnic populations or geographic regions.

\section{Conclusion}

In summary, this large prospective study added new insights into the role of meat consumptions toward BC carcinogenesis. It was found that organ meats may be a risk factor for the development of $\mathrm{BC}$, and fish might play a protective role against $\mathrm{BC}$ risk among men.

Supplementary Information The online version contains supplementary material available at https://doi.org/10.1007/s10654-021-00762-4.

Acknowledgements The study sponsors had no role in the design of the study; the collection, analysis, or interpretation of the data; the writing of the manuscript; or the decision to submit the manuscript for publication.

Author contributions $\mathrm{MD}, \mathrm{AW}, \mathrm{TDL}$, and $\mathrm{MZ}$ were involved in the study conceptualization, methodology, writing and editing the manuscript. AS, EY, MF, and MB helped in data analysis and manuscript review. PB, EW, EW, FC, MG, IH, FL, GS, AT, ER, GG and RM were involved in writing and editing the manuscript and providing critical feedback. All authors have read and agreed to the published version of the manuscript.

Funding This work was partly funded by the World Cancer Research Fund International (WCRF 2012/590) and European Commission (FP7-PEOPLE-618308).

Data availability Datasets that are minimally required to replicate the outcomes of the study will be made available upon reasonable request.

\section{Declarations}

Conflict of interest The authors declare that they have no conflict of interest. Where authors are identified as personnel of the International Agency for Research on Cancer/ World Health Organization, the authors alone are responsible for the views expressed in this article 
and they do not necessarily represent the decisions, policy or views of the International Agency for Research on Cancer/ World Health Organization.

Ethical approval Each participating study has been approved by the local ethic committee.

Informed consent Informed consent was obtained from all individual participants included in each study.

Open Access This article is licensed under a Creative Commons Attribution 4.0 International License, which permits use, sharing, adaptation, distribution and reproduction in any medium or format, as long as you give appropriate credit to the original author(s) and the source, provide a link to the Creative Commons licence, and indicate if changes were made. The images or other third party material in this article are included in the article's Creative Commons licence, unless indicated otherwise in a credit line to the material. If material is not included in the article's Creative Commons licence and your intended use is not permitted by statutory regulation or exceeds the permitted use, you will need to obtain permission directly from the copyright holder. To view a copy of this licence, visit http://creativecommons.org/licenses/by/4.0/.

\section{References}

1. Sung H, Ferlay J, Siegel RL, et al. Global cancer statistics 2020: GLOBOCAN estimates of incidence and mortality worldwide for 36 cancers in 185 countries. CA Cancer J Clin. 2021. https://doi. org/10.3322/caac. 21660 .

2. Parkin DM. The global burden of urinary bladder cancer. Scand $\mathbf{J}$ Urol Nephrol Suppl. 2008;42(218):12-20. https://doi.org/10.1080/ 03008880802285032.

3. Mossanen M, Gore JL. The burden of bladder cancer care: direct and indirect costs. Curr Opin Urol. 2014;24(5):487-91.

4. Al-Zalabani AH, Stewart KF, Wesselius A, Schols AM, Zeegers MP. Modifiable risk factors for the prevention of bladder cancer: a systematic review of meta-analyses. Eur J Epidemiol. 2016;31(9):811-51. https://doi.org/10.1007/s10654-016-0138-6.

5. Janković S, Radosavljević V. Risk factors for bladder cancer. Tumori J. 2007;93(1):4-12.

6. Clinton SK, Giovannucci EL, Hursting SD. The World Cancer Research Fund/American Institute for Cancer Research third expert report on diet, nutrition, physical activity, and cancer: impact and future directions. J Nutr. 2020;150(4):663-71.

7. Bogovski P, Bogovski S. Special report animal species in which n-nitroso compounds induce cancer. Int J Cancer. 1981;27(4):471-4.

8. Bryan GT. The pathogenesis of experimental bladder cancer. Cancer Res. 1977;37(8 Pt 2):2813-6.

9. Grosse Y, Baan R, Straif K, et al. Carcinogenicity of nitrate, nitrite, and cyanobacterial peptide toxins. Lancet Oncol. 2006;7(8):6289. https://doi.org/10.1016/s1470-2045(06)70789-6.

10. Mirvish SS. Role of N-nitroso compounds (NOC) and N-nitrosation in etiology of gastric, esophageal, nasopharyngeal and bladder cancer and contribution to cancer of known exposures to NOC. Cancer Lett. 1995;93(1):17-48. https://doi.org/10.1016/ 0304-3835(95)03786-V.

11. Dianatinasab M, Wesselius A, Salehi-Abargouei A, et al. Adherence to a Western dietary pattern and risk of bladder cancer: a pooled analysis of 13 cohort studies of the Bladder Cancer Epidemiology and Nutritional Determinants international study. Int J Cancer. 2020. https://doi.org/10.1002/ijc.33173.
12. Larsson SC, Johansson JE, Andersson SO, Wolk A. Meat intake and bladder cancer risk in a Swedish prospective cohort. Cancer Causes Control. 2009;20(1):35-40. https://doi.org/10.1007/ s10552-008-9214-x.

13. Ferrucci LM, Sinha R, Ward MH, et al. Meat and components of meat and the risk of bladder cancer in the NIH-AARP Diet and Health Study. Cancer. 2010;116(18):4345-53. https://doi.org/10. $1002 /$ cncr.25463.

14. $\mathrm{Xu} X$. Processed meat intake and bladder cancer risk in the prostate, lung, colorectal, and ovarian (PLCO) cohort. Cancer Epidemiol Biomarkers Prev. 2019;28(12):1993-7. https://doi.org/10. 1158/1055-9965.EPI-19-0604.

15. Crippa A, Larsson SC, Discacciati A, Wolk A, Orsini N. Red and processed meat consumption and risk of bladder cancer: a dose-response meta-analysis of epidemiological studies. Eur J Nutr. 2018;57(2):689-701.

16. Li F, An S, Hou L, Chen P, Lei C, Tan W. Red and processed meat intake and risk of bladder cancer: a meta-analysis. Int J Clin Exp Med. 2014;7(8):2100-10.

17. Goossens ME, Isa F, Brinkman M, et al. International pooled study on diet and bladder cancer: the bladder cancer, epidemiology and nutritional determinants (BLEND) study: design and baseline characteristics. Arch Public Health. 2016;74:30. https:// doi.org/10.1186/s13690-016-0140-1.

18. Riboli E, Kaaks R. The EPIC Project: rationale and study design. European Prospective Investigation into Cancer and Nutrition. Int J Epidemiol. 1997;26(Suppl 1):S6-14. https://doi.org/10.1093/ije/ 26.suppl_1.s6.

19. Tjonneland A, Olsen A, Boll K, et al. Study design, exposure variables, and socioeconomic determinants of participation in Diet, Cancer and Health: a population-based prospective cohort study of 57,053 men and women in Denmark. Scand J Public Health. 2007;35(4):432-41. https://doi.org/10.1080/14034940601047986.

20. Clavel-Chapelon F, van Liere MJ, Giubout C, et al. E3N, a French cohort study on cancer risk factors. E3N Group. Etude Epidemiologique aupres de femmes de l'Education Nationale. Eur J Cancer Prev. 1997;6(5):473-8. https://doi.org/10.1097/00008469199710000-00007.

21. Boeing H, Korfmann A, Bergmann MM. Recruitment procedures of EPIC-Germany. European Investigation into Cancer and Nutrition. Ann Nutr Metab. 1999;43(4):205-15. https://doi.org/ 10.1159/000012787.

22. Panico S, Dello Iacovo R, Celentano E, et al. Progetto ATENA, a study on the etiology of major chronic diseases in women: design, rationale and objectives. Eur J Epidemiol. 1992;8(4):601-8. https://doi.org/10.1007/BF00146383.

23. Beulens JW, Monninkhof EM, Verschuren WM, et al. Cohort profile: the EPIC-NL study. Int J Epidemiol. 2010;39(5):1170-8. https://doi.org/10.1093/ije/dyp217.

24. Lund E, Dumeaux V, Braaten T, et al. Cohort profile: the Norwegian Women and Cancer Study-NOWAC-Kvinner og kreft. Int J Epidemiol. 2008;37(1):36-41. https://doi.org/10.1093/ije/ dym 137.

25. Riboli E, Hunt KJ, Slimani N, et al. European Prospective Investigation into Cancer and Nutrition (EPIC): study populations and data collection. Public Health Nutr. 2002;5(6B):1113-24. https:// doi.org/10.1079/PHN2002394.

26. Manjer J, Carlsson S, Elmstahl S, et al. The Malmo Diet and Cancer Study: representativity, cancer incidence and mortality in participants and non-participants. Eur J Cancer Prev. 2001;10(6):489-99. https://doi.org/10.1097/00008469-20011 2000-00003.

27. Hallmans G, Agren A, Johansson G, et al. Cardiovascular disease and diabetes in the Northern Sweden Health and Disease Study Cohort-evaluation of risk factors and their interactions. Scand 
J Public Health Suppl. 2003;61:18-24. https://doi.org/10.1080/ 14034950310001432.

28. Davey GK, Spencer EA, Appleby PN, Allen NE, Knox KH, Key TJ. EPIC-Oxford: lifestyle characteristics and nutrient intakes in a cohort of 33883 meat-eaters and 31546 non meat-eaters in the UK. Public Health Nutr. 2003;6(3):259-69. https://doi.org/ 10.1079/PHN2002430.

29. Day N, Oakes S, Luben R, et al. EPIC-Norfolk: study design and characteristics of the cohort. European Prospective Investigation of Cancer. Br J Cancer. 1999;80(Suppl 1):95-103.

30. van den Brandt PA, Goldbohm RA, van't Veer P, Volovics A, Hermus RJ, Sturmans F. A large-scale prospective cohort study on diet and cancer in The Netherlands. J Clin Epidemiol. 1990;43(3):285-95. https://doi.org/10.1016/0895-4356(90) 90009-e.

31. White E, Patterson RE, Kristal AR, et al. VITamins And Lifestyle cohort study: study design and characteristics of supplement users. Am J Epidemiol. 2004;159(1):83-93. https://doi.org/10.1093/aje/ kwh010.

32. Percy C, Holten VV, Muir CS, Organization WH. International classification of diseases for oncology; 1990.

33. Percy C, Holten Vv, Muir CS, World Health O. In: Percy C, Van Holten V, Muir C, editors. International classification of diseases for oncology. 2nd ed. Geneva: World Health Organization; 1990.

34. Kaaks R, Riboli E. Validation and calibration of dietary intake measurements in the EPIC project: methodological considerations. European Prospective Investigation into Cancer and Nutrition. Int J Epidemiol. 1997;26(Suppl 1):S15-25. https://doi.org/10.1093/ije/ 26.suppl_1.s15.

35. Zeegers MP, Goldbohm RA, van den Brandt PA. Are retinol, vitamin $\mathrm{C}$, vitamin $\mathrm{E}$, folate and carotenoids intake associated with bladder cancer risk? Results from the Netherlands Cohort Study. Br J Cancer. 2001;85(7):977-83. https://doi.org/10.1054/bjoc.2001.1968.

36. Ferrari P, Slimani N, Ciampi A, et al. Evaluation of under- and overreporting of energy intake in the 24-hour diet recalls in the European Prospective Investigation into Cancer and Nutrition (EPIC). Public Health Nutr. 2002;5(6b):1329-45. https://doi.org/10.1079/phn20 02409.

37. Poortvliet E, Klensin J, Kohlmeier L. Rationale document for the Eurocode 2 food coding system (version 91/2). Eur J Clin Nutr. 1992;46(Suppl 5):S9-24.

38. Daniel CR, Cross AJ, Graubard BI, Hollenbeck AR, Park Y, Sinha R. Prospective investigation of poultry and fish intake in relation to cancer risk. Cancer Prev Res. 2011;4(11):1903-11.

39. Willett WC, Howe GR, Kushi LH. Adjustment for total energy intake in epidemiologic studies. Am J Clin Nutr. 1997;65(4):1220S-S1228.

40. Joshi AD, Kim A, Lewinger JP, et al. Meat intake, cooking methods, dietary carcinogens, and colorectal cancer risk: findings from the Colorectal Cancer Family Registry. Cancer Med. 2015;4(6):936-52. https://doi.org/10.1002/cam4.461.

41. Bagnardi V, Zambon A, Quatto P, Corrao G. Flexible metaregression functions for modeling aggregate dose-response data, with an application to alcohol and mortality. Am J Epidemiol. 2004;159(11):1077-86. https://doi.org/10.1093/aje/kwh142.

42. Isa F, Xie LP, Hu Z, et al. Dietary consumption and diet diversity and risk of developing bladder cancer: results from the South and East China case-control study. Cancer Causes Control. 2013;24(5):88595. https://doi.org/10.1007/s10552-013-0165-5.

43. Steinmaus CM, Nunez S, Smith AH. Diet and bladder cancer: a meta-analysis of six dietary variables. Am J Epidemiol. 2000;151(7):693-702. https://doi.org/10.1093/oxfordjournals.aje. a010264.

44. Brinkman M, Zeegers MP. Nutrition, total fluid and bladder cancer. Scand J Urol Nephrol Suppl. 2008;42(218):25-36. https://doi.org/ 10.1080/03008880802285073.
45. Lin J, Forman MR, Wang J, et al. Intake of red meat and heterocyclic amines, metabolic pathway genes and bladder cancer risk. Int $\mathbf{J}$ Cancer. 2012;131(8):1892-903. https://doi.org/10.1002/ijc. 27437.

46. Chiang VS-C, Quek S-Y. The relationship of red meat with cancer: Effects of thermal processing and related physiological mechanisms. Crit Rev Food Sci Nutr. 2017;57(6):1153-73.

47. Knize M, Andresen B, Healy S, et al. Effects of temperature, patty thickness and fat content on the production of mutagens in fried ground beef. Food Chem Toxicol. 1985;23(12):1035-40.

48. Di Maso M, Turati F, Bosetti C, et al. Food consumption, meat cooking methods and diet diversity and the risk of bladder cancer. Cancer Epidemiol. 2019;63:101595. https://doi.org/10.1016/j.canep.2019. 101595.

49. Hopkins HT, Murphy EW, Smith DP. Minerals and proximate composition of organ meats. J Am Diet Assoc. 1961;38:344-9.

50. Anderson-Otunu O, Akhtar S. Chronic infections of the urinary tract and bladder cancer risk: a systematic review. Asian Pac J Cancer Prev. 2016;17(8):3805-7.

51. Vermeulen SH, Hanum N, Grotenhuis AJ, et al. Recurrent urinary tract infection and risk of bladder cancer in the Nijmegen bladder cancer study. Br J Cancer. 2015;112(3):594-600. https://doi.org/10. 1038/bjc.2014.601.

52. Kjaer SK, Knudsen JB, Sorensen BL, Moller JO. The Copenhagen case-control study of bladder cancer. V. Review of the role of urinary-tract infection. Acta Oncol. 1989;28(5):631-6. https://doi. org/10.3109/02841868909092283.

53. Hoffmann D, Rivenson A, Abbi R, Wynder EL. A study of tobacco carcinogenesis: effect of the fat content of the diet on the carcinogenic activity of 4-(methylnitrosamino)-1-(3-pyridyl)-1-butanone in F344 rats. Can Res. 1993;53(12):2758-61.

54. Hebert JR, Kabat GC. Distribution of smoking and its association with lung cancer: implications for studies on the association of fat with cancer. J Natl Cancer Inst. 1991;83(12):872-5.

55. Taioli E, Nicolosi A, Wynder E. Possible role of diet as a host factor in the aetiology of tobacco-induced lung cancer: an ecological study in southern and northern Italy. Int J Epidemiol. 1991;20(3):611.

56. Hoffmann D, Adams J, Piade J, Hecht S. Chemical studies on tobacco smoke LXVIII. Analysis of volatile and tobacco-specific nitrosamines in tobacco products. IARC Sci Publ. 1980;31:507.

57. Wang C, Jiang H. Meat intake and risk of bladder cancer: a metaanalysis. Med Oncol. 2012;29(2):848-55. https://doi.org/10.1007/ s12032-011-9985-x.

58. Tappel A. Heme of consumed red meat can act as a catalyst of oxidative damage and could initiate colon, breast and prostate cancers, heart disease and other diseases. Med Hypotheses. 2007;68(3):562-4.

59. Baena AV, Allam MF, Del Castillo AS, et al. Urinary bladder cancer risk factors in men: a Spanish case-control study. Eur J Cancer Prev. 2006;15(6):498-503. https://doi.org/10.1097/01.cej.0000215618. 05757.04.

60. Larsson SC, Kumlin M, Ingelman-Sundberg M, Wolk A. Dietary long-chain n-3 fatty acids for the prevention of cancer: a review of potential mechanisms. Am J Clin Nutr. 2004;79(6):935-45. https:// doi.org/10.1093/ajen/79.6.935.

61. Holick CN, Giovannucci EL, Stampfer MJ, Michaud DS. A prospective study of fish, marine fatty acids, and bladder cancer risk among men and women (United States). Cancer Causes Control. 2006;17(9):1163-73. https://doi.org/10.1007/s10552-006-0059-x.

62. Li Z, Yu J, Miao Q, et al. The association of fish consumption with bladder cancer risk: a meta-analysis. World J Surg Oncol. 2011;9(1):107. https://doi.org/10.1186/1477-7819-9-107.

63. This part: World Cancer Research Fund/American Institute for Cancer Research. Continuous Update Project Expert Report 2018. Meat fadpatrocAa.dietandcancerreport.org. 
64. Michaud DS, Holick CN, Giovannucci E, Stampfer MJ. Meat intake and bladder cancer risk in 2 prospective cohort studies. Am J Clin Nutr. 2006;84(5):1177-83. https://doi.org/10.1093/ajcn/84.5.1177.

65. Flood A, Rastogi T, Wirfält E, et al. Dietary patterns as identified by factor analysis and colorectal cancer among middle-aged Americans. Am J Clin Nutr. 2008;88(1):176-84.

66. Koebnick C, Michaud D, Moore SC, et al. Body mass index, physical activity, and bladder cancer in a large prospective study. Cancer Epidemiol Biomarkers Prev. 2008;17(5):1214-21. https://doi.org/ 10.1158/1055-9965.EPI-08-0026.
67. Margetts B, Vorster H, Venter C. Evidence-based nutrition-the impact of information and selection bias on the interpretation of individual studies. South Afr J Clin Nutr. 2003;16:79.

Publisher's Note Springer Nature remains neutral with regard to jurisdictional claims in published maps and institutional affiliations. 